\title{
Resveratrol-mediated apoptosis in renal cell carcinoma via the p53/AMP-activated protein kinase/mammalian target of rapamycin autophagy signaling pathway
}

\author{
QINGJUN LIU ${ }^{1}$, QIANG FANG ${ }^{2}$, SHIQI JI ${ }^{1}$, ZHIXING HAN ${ }^{1}$, WENLONG CHENG ${ }^{1}$ and HAIJIAN ZHANG ${ }^{1}$ \\ ${ }^{1}$ Department of Urology, Beijing Ditan Hospital, Capital Medical Science, Beijing 100015; \\ ${ }^{2}$ Department of Urology, First Hospital of Fangshan District, Beijing 102400, P.R. China
}

Received May 10, 2017; Accepted August 31, 2017

DOI: $10.3892 / \mathrm{mmr} .2017 .7868$

\begin{abstract}
Resveratrol, known as phytoalexin, is a natural compound. Clinical studies have revealed that resveratrol has a variety of effects including anti-inflammatory, antivirus and tumor suppressor activities. It has been reported that it may serve an important role in renal cell carcinoma (RCC) however, the molecular mechanism underlying resveratrol-induced apoptosis in RCC is still unclear. The aim of the present study was to determine whether resveratrol could suppress RCC progression. Analysis of apoptosis demonstrated that resveratrol may act as a RCC suppressor in a dose- and time-dependent manner. In addition, the results of the MTT and cell migration experiments revealed that resveratrol significantly decreased cell viability and migration. In addition, the expression of the anti-apoptosis gene B-cell lymphoma 2 (Bcl-2) was downregulated by resveratrol, and the expression of pro-apoptosis gene Bcl-2-associated X was upregulated at the mRNA and protein levels. Resveratrol also promoted the expression of p53 and activated phospho-AMP-activated protein kinase (AMPK). The phosphorylation of mammalian target of rapamycin (mTOR) was inhibited and the autophagy-associated genes, light chain 3, autophagy related (ATG)5 and ATG7, were upregulated at the mRNA and protein levels. In conclusion, resveratrol suppressed RCC viability and migration, and promoted $\mathrm{RCC}$ apoptosis via the p53/AMPK/mTOR-induced autophagy signaling pathway.
\end{abstract}

\section{Introduction}

Renal cell carcinoma (RCC), a complex metabolic disease that is associated with a number of different types of cancer,

Correspondence to: Dr Qingjun Liu, Department of Urology, Beijing Ditan Hospital, Capital Medical Science, 8 Jingshun East Street, Chaoyang, Beijing 100015, P.R. China

E-mail: liuqingjun123@hotmail.com

Key words: resveratrol, renal cell carcinoma cell, p53, AMP-activated protein kinase, mammalian target of rapamycin, autophagy occurs in the kidney. In recent years, RCC has become the most common urological malignancy (1), accounting for $\sim 2-3 \%$ of adult malignancies and $\sim 80-90 \%$ of adult kidney malignancies; thus, RCC has a serious impact on public health. The current treatments available for RCC include novel small molecular targeted drugs, immune targeted therapy, adjuvant and neoadjuvant therapies and biomarker research. The primary treatments applied for RCC include tyrosine kinase inhibitors such as sunitinib and pazopanib, the mTOR inhibitor temsirolimus, the monoclonal antibody inhibitor of vascular endothelial growth factor (VEGF) bevacizumab and cytokine treatments such as aldesleukin (2). The current principle of targeted RCC therapy is based on the known molecular mechanisms of renal cancer and aims to prevent the proliferation of tumor cells and inhibit angiogenesis; Von Hippel-Lindau tumor suppressor and mTOR (3) are the widely used targets in clinical practice. p53, a tumor suppressor protein, serves an important role in apoptosis and the inhibition of angiogenesis; it is essential for mouse double minute 2 proto-oncogene antagonist induced RCC cell apoptosis (4). Recently, a previous study demonstrated that co-treatment with curcumin and temsirolimus activated the expression of p53, which induced RCC cell apoptosis (5). In addition, p53 crosslinking with transglutaminase 2 led to p53 depletion and tumor survival (6); these findings suggested that p53 may be a key regulator in $\mathrm{RCC}$.

mTOR is known as a serine-threonine kinase and the mTOR signaling pathway has been implicated in inflammatory, metabolic, degenerative and proliferative activities, and in cancer (7-10). It has been reported that mTOR is activated and hyperactivated in RCC (11). In addition, mTOR mutations have been observed in clear cell RCC (12). The results of these studies indicated that mTOR may have an important role in the regulation of RCC however, the molecular mechanism requires further investigation. Therefore, the present study will further evaluate the effect of mTOR in RCC.

Resveratrol (Trans-3,4',5-trihydroxystilbene) is a natural phytoalexin that is used to prevent human cardiovascular diseases, and induce anti-inflammatory $(13,14)$ and anticancer (15) activities. A previous study revealed that resveratrol is a promising therapy for patients with chronic kidney disease (16). Liu et al (17) demonstrated that insulin- and leucine-stimulated 
mTOR signaling was inhibited by resveratrol. However, another previous study indicated that resveratrol may negatively regulate mTOR via AMP-activated protein kinase (AMPK) activation in sensory neurons (18). In RCC cells, resveratrol may inhibit RCC cell proliferation and apoptosis via the angiotensin II receptor type 1/VEGF signaling pathway (19). Whether resveratrol is able to regulate RCC through the AMPK/mTOR signaling pathway requires further study. In the present study, resveratrol-mediated cell apoptosis in RCC through the p53 AMPK/mTOR signaling pathway is investigated in order to provide a potential target for the treatment of RCC.

\section{Materials and methods}

Cell culture. HK-2 and Ketr-3 cells were obtained from American Type Culture Collection (Manassas, VA, USA). The cells were maintained in Eagle's Minimum Essential Medium with $10 \%$ fetal bovine serum (FBS) (Hangzhou Sijiqing Biological Engineering Materials Co., Ltd., Hangzhou, China), and were cultured at $37^{\circ} \mathrm{C}$ in a $5 \%$ humidified $\mathrm{CO}_{2}$ atmosphere until they reached $90 \%$ confluence. Resveratrol was obtained from Sigma-Aldrich; Merck KGaA (Darmstadt, Germany) and was dissolved in DMSO in order to create a stock solution at a concentration of $100 \mathrm{mM}$; this was subsequently diluted in the culture medium to the desired concentration $(12.5,25,50$ and $100 \mu \mathrm{M}$ ) for experiments. DMSO was used as the blank control for all experiments.

Reverse transcription-quantitative polymerase chain reaction (RT-qPCR) analysis. Total RNA was extracted from Ketr cells after $48 \mathrm{~h}$ using TRIzol reagent (Invitrogen; Thermo Fisher Scientific, Inc., Waltham, MA, USA) after the cells were treated with resveratrol $(12.5,25,50$ and $100 \mu \mathrm{M})$ for $72 \mathrm{~h}$. The concentration of extracted RNA was determined using a spectrophotometer at wavelength of $260 \mathrm{~nm}$. Reverse transcription was performed using the PrimeScript ${ }^{\mathrm{TM}}$ RT reagent kit with gDNA Eraser (Perfect Real Time) according to the manufacturer's protocol (Takara Biotechnology Co., Ltd., Dalian, China). The reactions were as follows: $42^{\circ} \mathrm{C}$ for $60 \mathrm{~min}$, followed by $95^{\circ} \mathrm{C}$ for $5 \mathrm{~min}$. qPCR was performed using the SYBR Premix Ex Taq ${ }^{\mathrm{TM}}$ II reaction mixture (Takara Biotechnology Co., Ltd.). The thermocycling conditions were as follows: $95^{\circ} \mathrm{C}$ for $30 \mathrm{sec}$ for initial denaturation, then 40 cycles of $95^{\circ} \mathrm{C}$ for $5 \mathrm{sec}, 60^{\circ} \mathrm{C}$ for $30 \mathrm{sec}$ and $72^{\circ} \mathrm{C}$ for $30 \mathrm{sec}$, followed by a final extension at $72^{\circ} \mathrm{C}$ for $5 \mathrm{~min}$. PCR reactions were carried out using the ABI Step One Plus real-time PCR system (Applied Biosystems; Thermo Fisher Scientific, Inc.). The primer sequences used were as follows: B-cell lymphoma 2 (Bcl-2) sense, 5'-ACCAAGCTGAGC GAGTGTC-3' and antisense, 5'-ACAAAGATGGTCACG GTCTGCC-3'; Bcl-2-associated X (Bax) sense, 5'-ACCAAG CTGAGCGAGTGTC-3' and antisense, 5'-ACAAAGATG GTCACGGTCTGCC-3'; p53 sense, 5'-GTTTCCGTCTGG GCTTCTTG-3' and antisense, 5'-CCTGGGCATCCTTGAGT TCC-3'; light chain (LC)3 sense, 5'-TGTCCGACTTATTCG AGAGCAGCA-3' and antisense, 5'-TTCACCAACAGGAAG AAGGCCTGA-3'; autophagy related (ATG)5 sense, 5'-TCG TACATATCCTGGCAGGTTCGC-3' and antisense, 5'-GAA GTCGCAGGGGCGTTCCAT-3' and ATG7 sense, 5'-CAT TCCGCTATAGGCACCAT-3' and antisense, 5'-CGGCAA
AGGAGAGAACAAAG-3'. Relative gene expression was calculated using the $2^{-\Delta \Delta \mathrm{Cq}}$ method (20), and the results were normalized to those of $\beta$-actin (sense, 5'-AACCGCGAGAAG ATGACCCAGATCATGTTT-3' and antisense, 5'-AGCAGC CGTGGCCATCTCTTGCTCGAAGTC-3').

Western blot analysis. Ketr-3 cells were washed three times with cold PBS and proteins were extracted using ice-cold radioimmunoprecipitation buffer (containing 1\% proteinase inhibitor PMSF; Beyotime Institute of Biotechnology, Shanghai, China). Cells were centrifuged at $14,500 \mathrm{x}$ g for $10 \mathrm{~min}$ at $4^{\circ} \mathrm{C}$. A Bicinchoninic Acid Protein Assay kit (Beyotime Institute of Biotechnology, Shanghai, China) was used to determine total protein concentrations. Total proteins $(15 \mu \mathrm{g})$ were separated by $4-12 \%$ SDS-PAGE gel and then transferred onto a nitrocellulose membrane (EMD Millipore, Billerica, MA, USA). Membranes were blocked with 5\% non-fat dry milk for $2 \mathrm{~h}$ at room temperature. The membranes were then incubated with a diluted primary antibody at $4^{\circ} \mathrm{C}$ overnight; Bax (D2E11) rabbit (cat. no. 5023; 1:1,000), Bcl-2 (cat. no. 15071; 1:1,000), p53 (7F5) rabbit (cat. no. 2527, 1:1,000), phospho-AMPK $\alpha$ (Thr172) (40H9) rabbit mAb (cat. no. 2535S, 1:1,000), AMPK $\alpha$ (D63G4) rabbit mAb (cat. no. 5832S, 1:1,000), phospho-mTOR (Ser2448) (D9C2) rabbit (cat. no. 5536, 1:1,000) mTOR (7C10) rabbit mAb (cat. no. 2983, 1:1,000) LC3B (D11) XP ${ }^{\circledR}$ rabbit mAb (cat. no. 3868, 1:1,000) Atg5 (D5F5U) rabbit mAb (cat. no. 12994, 1:1,000) Atg7 (D12B11) rabbit mAb (cat. no. 8558, 1:1,000) GAPDH (D16H11) XP rabbit mAb (cat. no. 5174S, 1: $5,000)$. All the primary antibodies were purchased from Cell Signaling Technology, Inc. (Danvers, MA, USA). Anti- $\beta$-actin antibodies (cat. no. MAB-1501; 1:10,000) were obtained from EMD Millipore. Anti-rabbit horseradish peroxidase-conjugated IgG antibodies (cat. no. ADI-SAB-300; 1:2,000) were purchased from Enzo Life Sciences, Inc. (Farmingdale, NY, USA) and incubated with the membrane for $2 \mathrm{~h}$ at room temperature. The specific complexes were visualized using the SuperSignal West Pico chemiluminescent substrate (Shanghai Solarbio Science and Technology, Shanghai, China). Densitometric analysis was performed to quantify the signal intensity using ImageJ software (version 1.37; National Institutes of Health, Bethesda, MD, USA).

MTT assay. Ketr-3 cell viability was measured using an MTT assay. Briefly, $1 \times 10^{6}$ cells were seeded into 96 -well plates, and following $24 \mathrm{~h}$ at $37^{\circ} \mathrm{C}$ to allow for cell adhesion, resveratrol was added at varying concentrations $(12.5,25,50$ and $100 \mu \mathrm{M})$ for 12, 24, 48 and $72 \mathrm{~h}$. Control cultures were treated with DMSO. A total of $20 \mu \mathrm{l}$ of $5 \mathrm{mg} / \mathrm{ml}$ MTT solution was added to each well and the plate was further incubated at $37^{\circ} \mathrm{C}$ for $4 \mathrm{~h}$. The cells were then washed with PBS and $150 \mu 1$ DMSO was added to each well. Absorbance was read at $570 \mathrm{~nm}$ using a spectrophotometer (EnSpire 2300 Multilabel Reader; PerkinElmer, Inc., Waltham, MA, USA).

Apoptosis assay. Tumor cells were digested with trypsin at $37^{\circ} \mathrm{C}$ for $5 \mathrm{~min}$ and inoculated in a $50 \mathrm{ml}$ culture flask at $5 \times 10^{5} / \mathrm{ml}$, then $1 \times 10^{5}$ Ketr-3 cells in each group were seeded in 6-well plates and treated with various concentrations of resveratrol $(12.5,25,50$ and $100 \mu \mathrm{M})$ for $24 \mathrm{~h}$; control cells treated with DMSO only. Cell apoptosis rate was detected 
using an Annexin V-fluorescein isothiocyanate (FITC)/propidium iodide (PI) Assay kit (BD Pharmingen; BD Biosciences, San Jose, CA, USA), according to the manufacturer's protocol. A BD FACSCanto II flow cytometer (BD Biosciences) was used to collect data for analysis using FCSExpress software (version 3.0; De Novo Software, Glendale, CA, USA).

Cell migration assay. Ketr-3 cells $\left(1 \times 10^{5}\right)$ after treatment with resveratrol $(12.5,25,50$ and $100 \mu \mathrm{M})$ were seeded in the top chamber of Transwell migration chambers $(8-5 \mathrm{~mm}$; BD Biosciences) in serum-free medium, and the lower chamber contained $10 \%$ FBS. Following culture for $24 \mathrm{~h}$ at $37^{\circ} \mathrm{C}$, the cells in the bottom chamber were stained with $0.1 \%$ crystal violet (Sigma-Aldrich; Merck $\mathrm{KGaA}$ ) at $37^{\circ} \mathrm{C}$ for $20 \mathrm{~min}$. The cells were then evaluated by a light microscopy (CK40; Olympus Corporation, Tokyo, Japan) at the magnification at x200. Images were captured, then the cells were counted randomly in five fields and the average was calculated.

Statistical analysis. The results were analyzed using SPSS software version 19.0 (IBM Corp., Armonk, NY, USA). Data are presented as the mean \pm standard deviation of at least three independent experiments. An analysis of variance followed by a Tukey test was performed to compare the differences between the different groups. $\mathrm{P}<0.05$ was considered to indicate a statistically significant difference.

\section{Results}

Effect of resveratrol on Ketr-3 cell viability. To investigate the effects of resveratrol on RCC cells, Ketr-3 cells were treated with various concentrations $(0,12.5,25,50$ and $100 \mu \mathrm{M})$ of resveratrol for 12, 24, 48 and $72 \mathrm{~h}$. Following treatment, cells were assayed by MTT and the results revealed that the Ketr-3 cell proliferation was significantly inhibited by resveratrol in a dose dependent manner (Fig. 1).

Resveratrol treatment inhibits Ketr-3 cell migration. To further evaluate the potential effect of resveratrol, it's effect on Ketr-3 cell migration was determined by measuring the number of migratory Ketr-3 cells following resveratrol treatment. As shown in Fig. 2, the number of migrating Ketr-3 cells was significantly inhibited by resveratrol in a dose-dependent manner.

Resveratrol induces apoptosis in Ketr-3 cells. Previous studies have demonstrated that resveratrol induces apoptosis in cancer cells (21-24). The present study further confirmed the ability of resveratrol to induce apoptosis in Ketr-3 cells. Annexin V-FITC/PI staining was performed to detect the effect of resveratrol treatment on apoptosis in cells. The results shown in Fig. 3 revealed that resveratrol treatment significantly increased cell apoptosis. As Bcl-2 and Bax are markers of apoptosis in RCC (25), the present study detected their mRNA and protein expression. Resveratrol treatment increased and decreased the expression of Bax and Bcl-2, respectively, at both the mRNA and protein levels (Fig. 4A and B). The results indicated that resveratrol may serve as a tumor suppressor in RCC.

Expression of p53 is downregulated in Ketr-3 cells and upregulated by treatment with resveratrol. The resveratrol

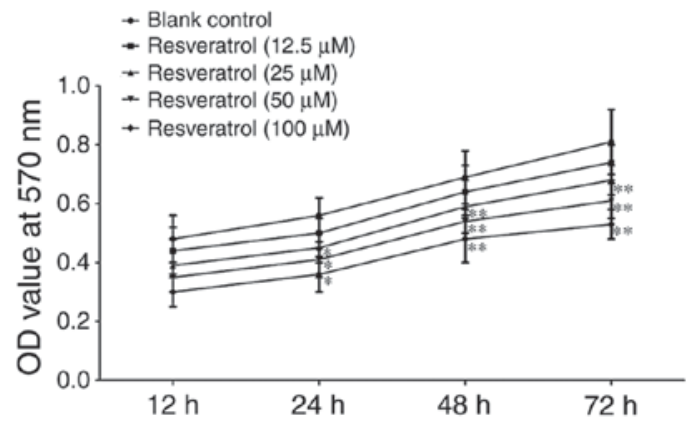

Figure 1. Resveratrol inhibits the Ketr-3 cell viability. Cells were seeded in a 96 -well plate and treated with resveratrol at various concentrations $(0,12.5$, 25,50 and $100 \mu \mathrm{M}$ ) and detected by MTT assay at 12, 24, 48 and $72 \mathrm{~h}$. DMSO was used as the blank control. Data are presented as the mean \pm standard deviation. ${ }^{*} \mathrm{P}<0.05$ and ${ }^{* *} \mathrm{P}<0.01$ vs. blank control. OD, optical density.

treatment significantly increased the expression of p53 mRNA and protein in a dose-dependent manner (Fig. 4C). However, when compared with the normal kidney HK-2 cells, the expression of p53 was significantly decreased in Ketr-3 cells (Fig. 5). These results indicated that $\mathrm{p} 53$ may serve an important role in resveratrol-induced Ketr-3 cell apoptosis.

Resveratrol induces Ketr-3 cell apoptosis through p53-mediated AMPK/mTOR signaling. Recently previous findings have indicated that AMPK may serve a pivotal role in the control of the p53 signaling pathway (26-28), however, it is unknown whether AMPK is involved in resveratrol-mediated Ketr-3 cell apoptosis. The present study detected the expression of AMPK and demonstrated that resveratrol treatment upregulated phosphorylated (p)-AMPK (Fig. 6A), which indicated that resveratrol may activate p-AMPK and regulate downstream gene expression. As mTOR is key in the p53 signaling pathway, the present study detected the expression of mTOR and demonstrated that resveratrol treatment downregulated p-mTOR, however, not the total expression of mTOR (Fig. 6B). Thus, resveratrol may induce Ketr-3 cell apoptosis via the p53-mediated AMPK/mTOR signaling.

Resveratrol mediated apoptosis in renal cell carcinoma cell potentially by promoting autophagy. Previous studies have revealed that the AMPK/mTOR signaling pathway is important in autophagy, however, it is not clear whether resveratrol regulates RCC though autophagy $(17,18,29)$. The present study detected the expression of the downstream genes of the AMPK/mTOR-induced autophagy pathway. The results revealed that the expression of LC3 (Fig. 7A), ATG5 (Fig. 7B) and ATG7 (Fig. 7C) were increased by resveratrol. These results suggested that p53 may regulate autophagy via AMPK/mTOR signaling, thereby promoting cell apoptosis.

\section{Discussion}

Previous studies have demonstrated that resveratrol acts as an anticancer factor in leukemia, and breast, stomach, colon, prostate, ovarian and skin cancer $(21,22,29-31)$. The results of these studies all indicated that resveratrol could effectively inhibit cancer cell activity, and that it could be used for chemoprevention and anti-inflammation (23). In addition, resveratrol 

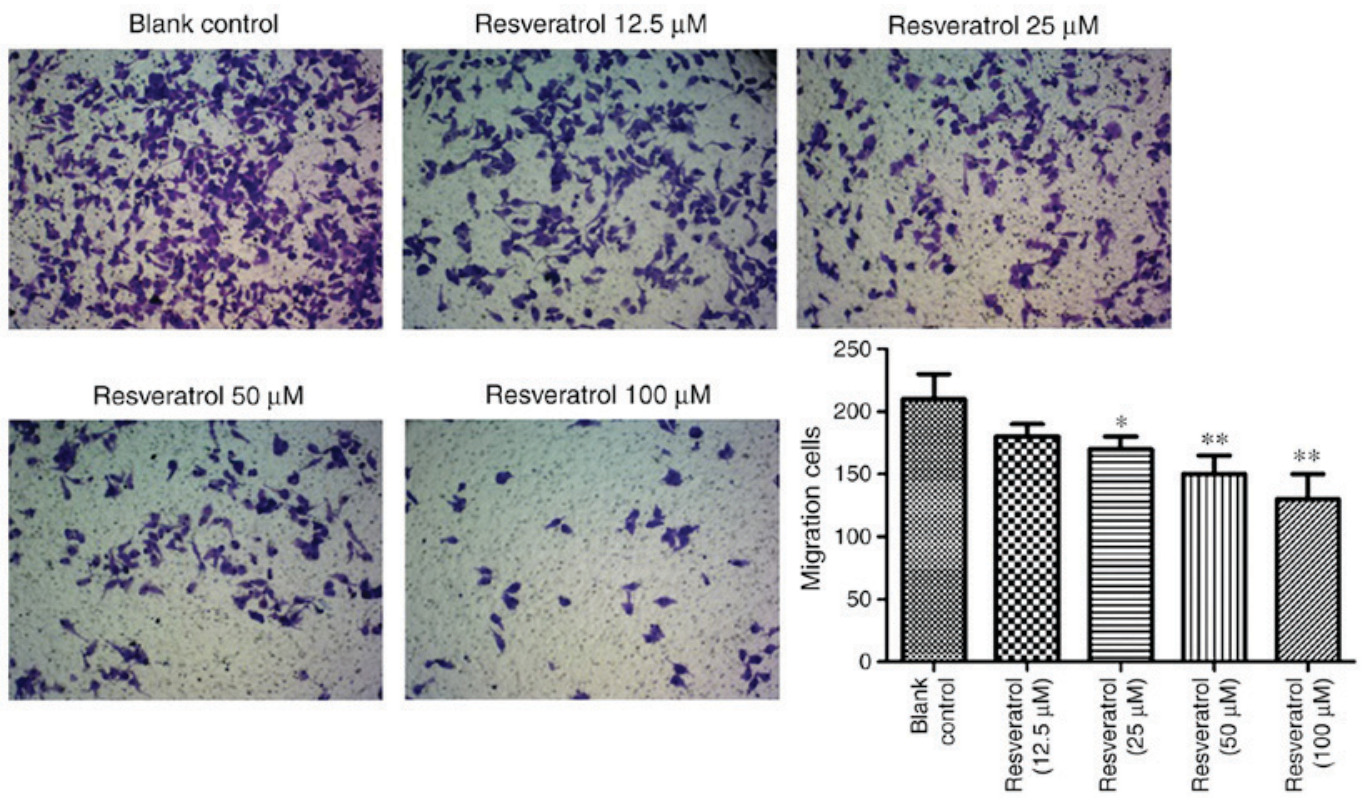

Figure 2. Migration of Ketr-3 cells is inhibited by resveratrol. Different concentrations of resveratrol $(0,12.5,25,50$ and $100 \mu \mathrm{M})$ were used to treat Ketr-3 cells and cell migration was detected by a cell migration assay. Magnification, x200. DMSO was used as the blank control. Data are presented as the mean \pm standard deviation. ${ }^{*} \mathrm{P}<0.05$ and ${ }^{* *} \mathrm{P}<0.01$ vs. blank control.
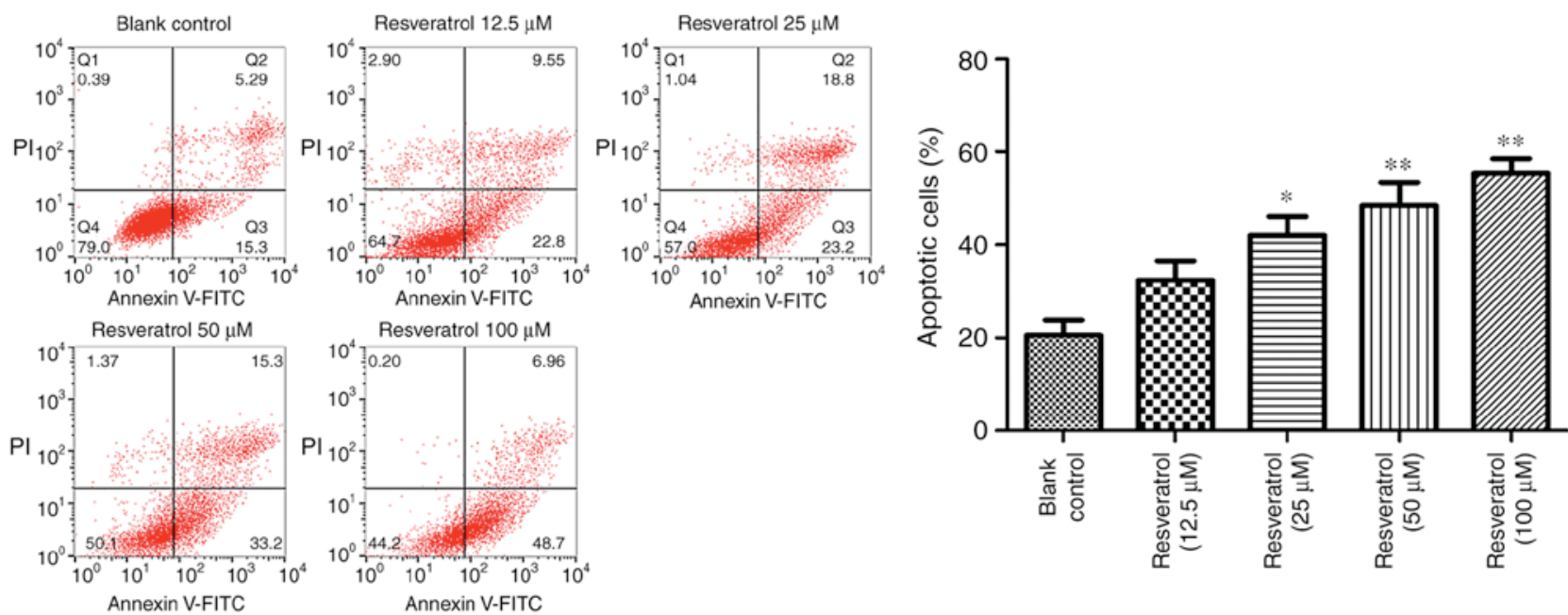

Figure 3. Different concentrations of resveratrol induce Ketr-3 cell apoptosis. Cells were treated with resveratrol at various concentrations $(0,12.5,25,50$ and $100 \mu \mathrm{M}$ ), then cell apoptosis was measured by flow cytometry. DMSO was used as the blank control. Data are presented as the mean \pm standard deviation. ${ }^{*} \mathrm{P}<0.05$ and ${ }^{* *} \mathrm{P}<0.01$ vs. blank control. FITC, fluorescein isothiocyanate; PI, propidium iodide.

prevented malignant tumor invasion by preventing kinase function $(31,32)$. In the present study, resveratrol induced RCC cell apoptosis, and inhibited cell viability and migration, which is consistent with the previous report (19). In addition, the present study also demonstrated that resveratrol may induce RCC apoptosis via the AMPK/mTOR autophagy pathway.

A previous study revealed that $\mathrm{p} 53$ was involved in resveratrol-induced cancer cell apoptosis (24). Resveratrol treatment in human breast cancer MCF-7 cells increased the expression of p53 and Bax/Bcl-2, and resveratrol can be used as a neo-adjuvant in human breast cancer (33). In addition, it has been reported that resveratrol can inhibit Glioblastoma multiforme growth by modulating $\mathrm{p} 53$ and protein kinase $\mathrm{B}$ (32). In RCC, p53 is a factor involved in cell-cycle arrest and apoptosis; although resveratrol has been reported to be associated with RCC, the specific role of p53 in resveratrol anti-RCC remains unknown (34). In the present study, the expression of p53, as well as Bax, was significantly upregulated in resveratrol-induced RCC cell apoptosis. The results of the present study are consistent with those of a previous study, which observed transglutaminase 2-induced p53 mediated apoptosis in RCC (35).

The AMPK-targeting drug 5-Aminoimidazole-4carboxamide riboside (26) and metformin may be used in clinical oncology (36). AMPK is a key regulator in cell growth and RCC tumorigenesis, and also when AMPK activation inhibits RCC growth and survival (26). In RCC, 8-chloroadenosine activated AMPK and inhibited mTOR pathway, and Silibinin, as a cancer chemopreventive flavonoid, could induce an anti-metastatic effect on RCC by targeting AMPK (37). In the present study, the levels of p-AMPK were upregulated 

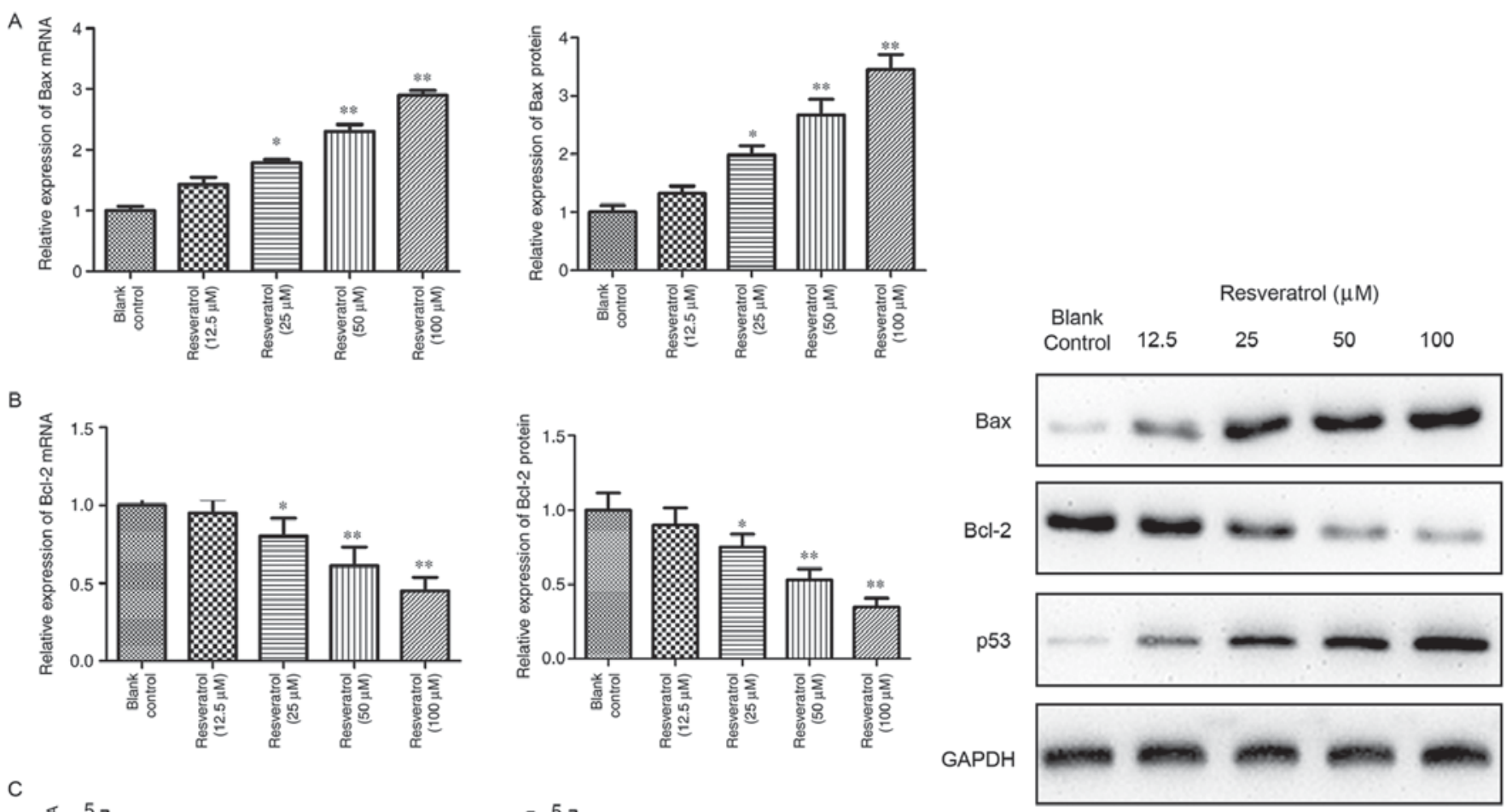

C
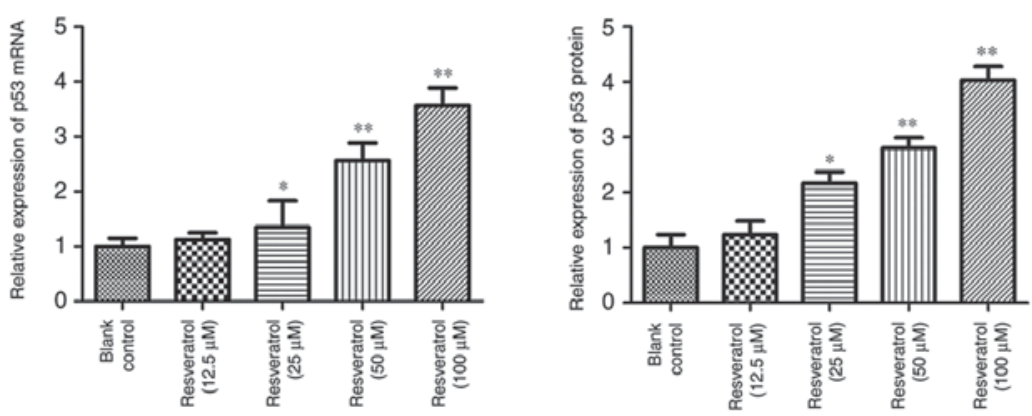

Figure 4. Expression of Bax, Bcl-2 and p53 in Ketr-3 cells treated with resveratrol. The relative mRNA and protein levels of (A) Bax, (B) Bcl-2 and (C) p53 were measured in Ketr-3 cells treated with 0,12.5, 25, 50 and $100 \mu \mathrm{M}$ resveratrol. mRNA was normalized to $\beta$-actin. DMSO was used as the blank control. Data are presented as the mean \pm standard deviation. ${ }^{*} \mathrm{P}<0.05$ and ${ }^{* *} \mathrm{P}<0.01$ vs. blank control. Bcl-2, B-cell lymphoma 2; Bax, Bcl-2-associated X.

A

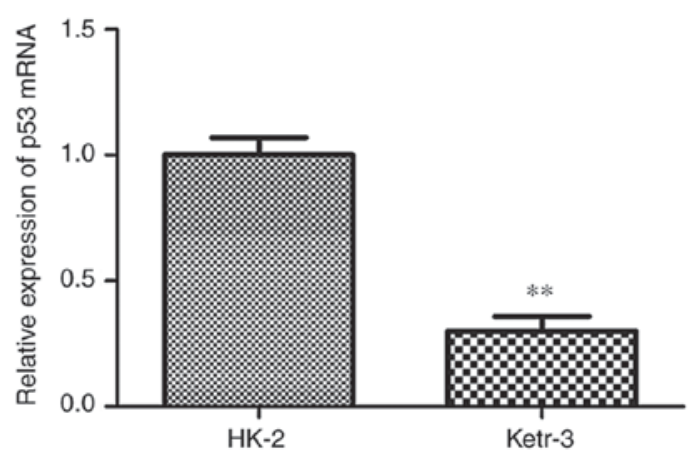

B

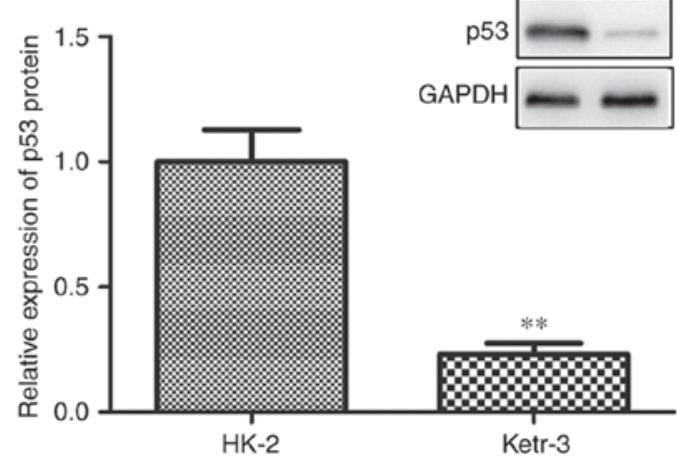

Figure 5. mRNA and protein expression of p53 in HK-2 and Ketr-3 cells. The relative (A) mRNA and (B) protein expression levels of p53 in normal HK-2 and Kert-3 cells. $\beta$-actin and GAPDH were used as internal controls for mRNA and protein expression, respectively. DMSO was used as the blank control. Data are presented as the mean \pm standard deviation. ${ }^{* *} \mathrm{P}<0.01$ vs. blank control.

following treatment with resveratrol; thus, AMPK may participate in the apoptosis induced by resveratrol.

Autophagy regulation involves a variety of different signaling pathways, of which, AMPK and mTOR are key regulators. AMPK promotes and mTOR inhibits autophagy (38).
In Zucker diabetic fatty rats, liraglutide promotes autophagy by enhancing AMPK phosphorylation and inhibiting mTOR phosphorylation (27). In addition, in cancer cells induced by wild-type p53, docosahexaenoic acid attenuates autophagy by increasing AMPK activation and decreasing the activity 

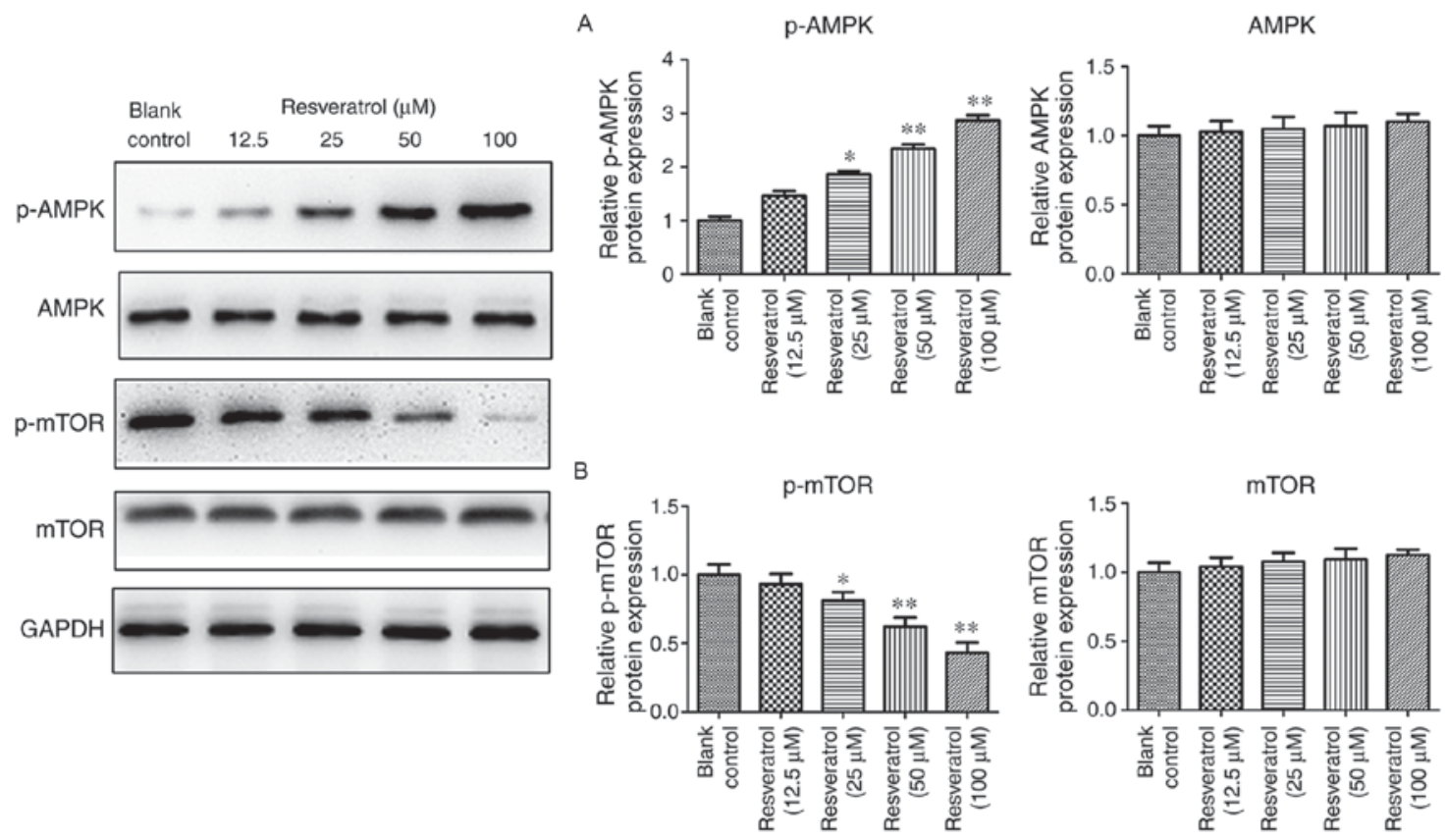

Figure 6. Effect of resveratrol on AMPK and mTOR protein expression. Cells were treated with $0,12.5,25,50$ and $100 \mu \mathrm{M}$ resveratrol and then the relative protein expression of (A) total and p-AMPK, and (B) total and p-mTOR was determined. Protein levels were normalized to those of GAPDH. DMSO was used as the blank control. Data are presented as the mean \pm standard deviation. ${ }^{*} \mathrm{P}<0.05$ and ${ }^{* *} \mathrm{P}<0.01$ vs. blank control. AMPK, AMP-activated protein kinase; mTOR, mammalian target of rapamycin; p-, phosphorylated.

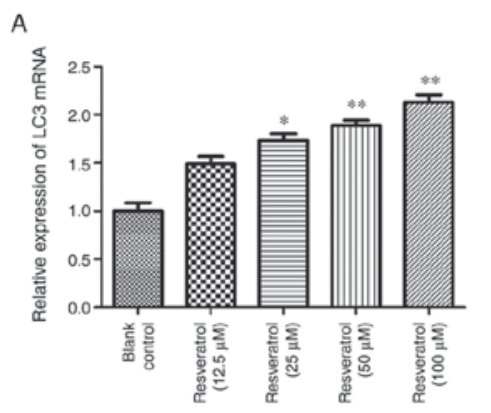

B

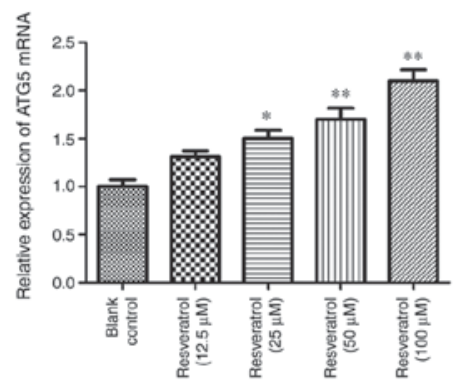

C

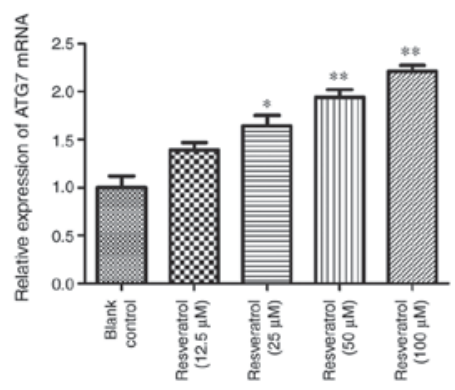

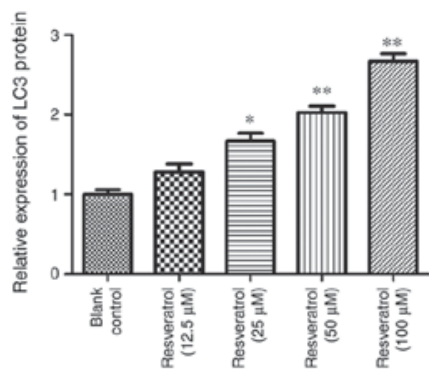

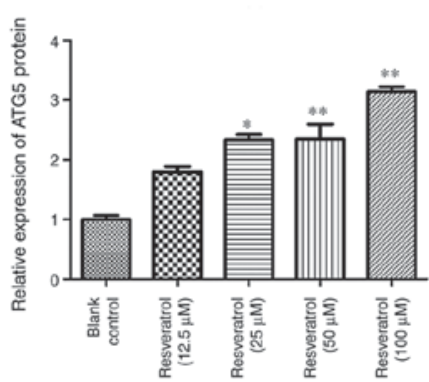

LC3

Blank

Resveratrol $(\mu \mathrm{M})$

Control $\quad 12.5 \quad 25 \quad 50$

ATG5
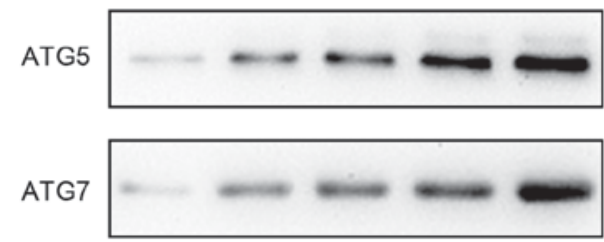

GAPDH

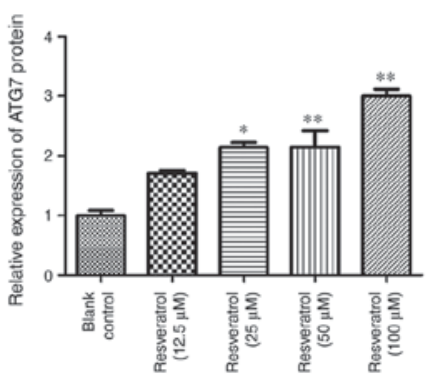

Figure 7. Autophagy is involved in resveratrol induced Kert-3 cell apoptosis. The relative mRNA and protein of (A) LC3, (B) ATG5 and (C) ATG7 were measured in cells treated with different concentrations of resveratrol $(0,12.5,25,50$ and $100 \mu \mathrm{M})$. DMSO was used as the blank control. Data are presented as the mean \pm standard deviation. ${ }^{*} \mathrm{P}<0.05$ and ${ }^{* *} \mathrm{P}<0.01$ vs. blank control. LC3, light chain 3 ; ATG, autophagy related. 
of mTOR (28). The present study detected the expression of the genes, LC3, ATG5 and ATG7, which are associated with autophagy. The results demonstrated that resveratrol upregulated their mRNA and protein levels, indicating that resveratrol may be involved in autophagy regulation in RCC. However, the role of resveratrol in the regulation of autophagy, in RCC or other human cancers, has yet to be elucidated.

In conclusion, the present study demonstrated that resveratrol treatment in RCC promoted apoptosis via p53-mediated AMPK/mTOR autophagy signaling. These results indicate that resveratrol may be a potential candidate for RCC treatment.

\section{Acknowledgements}

The present study was supported by the National Natural Science Funds of China (grant no. 81202029).

\section{References}

1. Mitsunari K, Miyata Y, Watanabe SI, Asai A, Yasuda T, Kanda S and Sakai H: Stromal expression of Fer suppresses tumor progression in renal cell carcinoma and is a predictor of survival. Oncol Lett 13: 834-840, 2017.

2. Merza $\mathrm{H}$ and Bilusic M: Current management strategy for metastatic renal cell carcinoma and future directions. Curr Oncol Rep 19: 27, 2017.

3. Cho D, Signoretti S, Dabora S, Regan M, Seeley A, Mariotti M, Youmans A, Polivy A, Mandato L, McDermott D, et al: Potential histologic and molecular predictors of response to temsirolimus in patients with advanced renal cell carcinoma. Clin Genitourin Cancer 5: 379-385, 2007.

4. Abolhasani M, Salarinejad S and Asgari M: P53 and MDM2 Over-expression and five-year survival of kidney cancer patients undergoing radical nephrectomy-iranian experience. Asian Pac J Cancer Prev 16: 5043-5047, 2015.

5. Xu S, Yang Z, Fan Y, Guan B, Jia J, Gao Y, Wang K, Wu K, Wang X,Zheng P, et al: Curcumin enhances temsirolimus-induced apoptosis in human renal carcinoma cells through upregulation of YAP/p53. Oncol Lett 12: 4999-5006, 2016.

6. Kang JH, Lee JS, Hong D, Lee SH, Kim N, Lee WK, Sung TW, Gong YD and Kim SY: Renal cell carcinoma escapes death by p53 depletion through transglutaminase 2-chaperoned autophagy. Cell Death Dis 7: e2163, 2016.

7. Habib SL and Liang S: Hyperactivation of Akt/mTOR and deficiency in tuberin increased the oxidative DNA damage in kidney cancer patients with diabetes. Oncotarget 5: 2542-2550, 2014.

8. Lamming DW and Sabatini DM: A Central role for mTOR in lipid homeostasis. Cell Metab 18: 465-469, 2013.

9. Kim YC and Guan KL: mTOR: A pharmacologic target for autophagy regulation. J Clin Invest 125: 25-32, 2015.

10. Xu J,Pham CG, Albanese SK, Dong Y, Oyama T, Lee CH, RodrikOutmezguine V, Yao Z, Han S, Chen D, et al: Mechanistically distinct cancer-associated mTOR activation clusters predict sensitivity to rapamycin. J Clin Invest 126: 3526-3540, 2016.

11. Pal SK and Quinn DI: Differentiating mTOR inhibitors in renal cell carcinoma. Cancer Treat Rev 39: 709-719, 2013.

12. Garcia-Donas J, Rodriguez-Antona C and Jonasch E: Molecular markers to predict response to therapy. Semin Oncol 40: 444-458, 2013.

13. Conte E, Fagone E, Fruciano M, Gili E, Iemmolo M and Vancheri C: Anti-inflammatory and antifibrotic effects of resveratrol in the lung. Histol Histopathol 30: 523-529, 2015.

14. Bo S, Ciccone G, Castiglione A, Gambino R, De Michieli F, Villois P, Durazzo M, Cavallo-Perin P and Cassader M: Anti-inflammatory and antioxidant effects of resveratrol in healthy smokers a randomized, double-blind, placebo-controlled, cross-over trial. Curr Med Chem 20: 1323-1331, 2013.

15. Wong JC and Fiscus RR: Resveratrol at anti-angiogenesis/anticancer concentrations suppresses protein kinase $\mathrm{G}$ signaling and decreases IAPs expression in HUVECs. Anticancer Res 35: 273-281, 2015.

16. Saldanha JF, Leal Vde O, Stenvinkel P, Carraro-Eduardo JC and Mafra D: Resveratrol: Why is it a promising therapy for chronic kidney disease patients? Oxid Med Cell Longev 2013: 963217, 2013
17. Liu M and Liu F: Resveratrol inhibits mTOR signaling by targeting DEPTOR. Commun Integr Biol 4: 382-384, 2011.

18. Tillu DV, Melemedjian OK, Asiedu MN, Qu N, De Felice M, Dussor G and Price TJ: Resveratrol engages AMPK to attenuate ERK and mTOR signaling in sensory neurons and inhibits incision-induced acute and chronic pain. Mol Pain 8: 5, 2012.

19. Li J, Qiu M, Chen L, Liu L, Tan G and Liu J: Resveratrol promotes regression of renal carcinoma cells via a renin-angiotensin system suppression-dependent mechanism. Oncol Lett 13: 613-620, 2017.

20. Livak KJ and Schmittgen TD: Analysis of relative gene expression data using real-time quantitative PCR and the 2(-Delta Delta C(T)) methods. Methods 25: 402-408, 2001.

21. Kai L, Samuel SK and Levenson AS: Resveratrol enhances p53 acetylation and apoptosis in prostate cancer by inhibiting MTA1/NuRD complex. Int J Cancer 126: 1538-1548, 2010.

22. Zhong LX, Zhang Y, Wu ML, Liu YN, Zhang P, Chen XY, Kong QY, Liu J and Li H: Resveratrol and STAT inhibitor enhance autophagy in ovarian cancer cells. Cell Death Discov 2: 15071, 2016.

23. Singh SK, Banerjee S, Acosta EP, Lillard JW and Singh R: Resveratrol induces cell cycle arrest and apoptosis with docetaxel in prostate cancer cells via a p53/ p21WAF1/CIP1 and p27KIP1 pathway. Oncotarget 8: 17216-17228, 2017.

24. Heiss EH, Schilder YD and Dirsch VM: Cvs. J Biol Chem 282: 26759-26766, 2007.

25. Saker Z, Tsintsadze O, Jiqia I, Managadze L and Chkhotua A: Importance of apoptosis markers (MDM2, BCL-2 and BAX) in conventional renal cell carcinoma. Georgian Med News: 27-33, 2015.

26. Woodard J, Joshi S, Viollet B, Hay N and Platanias LC: AMPK as a therapeutic target in renal cell carcinoma. Cancer Biol Ther 10: 1168-1177, 2010.

27. Zhang Y, Ling Y, Yang L, Cheng Y, Yang P, Song X, Tang H, Zhong Y, Tang L, He S, et al: Liraglutide relieves myocardial damage by promoting autophagy via AMPK-mTOR signaling pathway in zucker diabetic fatty rat. Mol Cell Endocrinol 448: 98-107, 2017.

28. Jing K, Song KS, Shin S, Kim N, Jeong S, Oh HR, Park JH, Seo KS, Heo JY, Han J, et al: Docosahexaenoic acid induces autophagy through $\mathrm{p} 53 / \mathrm{AMPK} / \mathrm{mTOR}$ signaling and promotes apoptosis in human cancer cells harboring wild-type p53. Autophagy 7: 1348-1358, 2011.

29. Park SY, Chae SY, Park JO, Lee KJ and Park G: Gold-conjugated resveratrol nanoparticles attenuate the invasion and MMP-9 and COX-2 expression in breast cancer cells. Oncol Rep 35: 3248-3256, 2016

30. Jing X, Cheng W, Wang S, Li P and He L: Resveratrol induces cell cycle arrest in human gastric cancer MGC803 cells via the PTEN-regulated PI3K/Akt signaling pathway. Oncol Rep 35: 472-478, 2016.

31. Liu B, Zhou Z, Zhou W, Liu J, Zhang Q, Xia J, Liu J, Chen N, $\mathrm{Li} \mathrm{M}$ and Zhu R: Resveratrol inhibits proliferation in human colorectal carcinoma cells by inducing G1/S-phase cell cycle arrest and apoptosis through caspase/cyclin-CDK pathways. Mol Med Rep 10: 1697-1702, 2014.

32. Clark PA, Bhattacharya S, Elmayan A, Darjatmoko SR, Thuro BA, Yan MB, van Ginkel PR, Polans AS and Kuo JS: Resveratrol targeting of AKT and p53 in glioblastoma and glioblastoma stem-like cells to suppress growth and infiltration. J Neurosurg 126: 1448-1460, 2016.

33. Ku BM, Kim DS, Kim KH, Yoo BC, Kim SH, Gong YD and Kim SY: Transglutaminase 2 inhibition found to induce p53 mediated apoptosis in renal cell carcinoma. FASEB J 27: 3487-3495, 2013

34. Shi T, Liou LS, Sadhukhan P, Duan ZH, Novick AC, Hissong JG, Almasan A and DiDonato JA: Effects of resveratrol on gene expression in renal cell carcinoma. Cancer Biol Ther 3: 882-888, 2004.

35. Mondal A and Bennett LL: Resveratrol enhances the efficacy of sorafenib mediated apoptosis in human breast cancer MCF7 cells through ROS, cell cycle inhibition, caspase 3 and PARP cleavage. Biomed Pharmacother 84: 1906-1914, 2016.

36. Ben Sahra I, Le Marchand-Brustel Y, Tanti JF and Bost F: Metformin in cancer therapy: A new perspective for an old antidiabetic drug? Mol Cancer Ther 9: 1092-1099, 2010.

37. Li F, Ma Z, Guan Z, Chen Y, Wu K, Guo P, Wang X, He D and Zeng J: Autophagy induction by silibinin positively contributes to its anti-metastatic capacity via AMPK/mTOR pathway in renal cell carcinoma. Int J Mol Sci 16: 8415-8429, 2015.

38. Das G, Shravage BV and Baehrecke EH: Regulation and function of autophagy during cell survival and cell death. Cold Spring Harb Perspect Biol 4: pii: a008813, 2012. 